\title{
Development of an operational modeling system for urban heat islands: an application to Athens, Greece
}

\author{
T. M. Giannaros ${ }^{1}$, D. Melas ${ }^{1}$, I. A. Daglis ${ }^{2, *}$, and I. Keramitsoglou ${ }^{2}$ \\ ${ }^{1}$ Aristotle University of Thessaloniki, School of Physics, Laboratory of Atmospheric Physics, P.O. Box 149, 54124, \\ Thessaloniki, Greece \\ ${ }^{2}$ National Observatory of Athens, Institute for Astronomy, Astrophysics, Space Applications and Remote Sensing, Vas. \\ Pavlou \& Metaxa, 15236, Athens, Greece \\ *now at: Department of Physics, University of Athens, 15784, Athens, Greece
}

Correspondence to: T. M. Giannaros (thgian@auth.gr)

Received: 27 August 2013 - Published in Nat. Hazards Earth Syst. Sci. Discuss.: 25 September 2013

Revised: 4 January 2014 - Accepted: 18 January 2014 - Published: 21 February 2014

\begin{abstract}
The urban heat island (UHI) effect is one prominent form of localized anthropogenic climate modification. It represents a significant urban climate problem since it occurs in the layer of the atmosphere where almost all daily human activities take place. This paper presents the development of a high-resolution modeling system that could be used for simulating the UHI effect in the context of operational weather forecasting activities. The modeling system is built around a state-of-the-art numerical weather prediction model, properly modified to allow for the better representation of the urban climate. The model performance in terms of simulating the near-surface air temperature and thermal comfort conditions over the complex urban area of Athens, Greece, is evaluated during a 1.5 -month operational implementation in the summer of 2010. Results from this case study reveal an overall satisfactory performance of the modeling system. The discussion of the results highlights the important role that, given the necessary modifications, a meteorological model can play as a supporting tool for developing successful heat island mitigation strategies. This is further underlined through the operational character of the presented modeling system.
\end{abstract}

\section{Introduction}

Urban expansion results in significant land cover changes. As cities sprawl into the natural habitat, roads, buildings and other structures, necessary to accommodate growing popu- lations, replace vegetation and natural surfaces. Such land cover changes significantly influence the local climate and weather. This has been extensively documented in the scientific literature, so that climatologists consider cities to have unique local climates, much like forests, lakes, valleys and coastlines.

The urban heat island (UHI) effect, describing the excess warmth of the urban atmosphere compared to the rural surroundings (Voogt and Oke, 2003), is one prominent and welldocumented environmental problem associated with urbanization. It is a phenomenon that is significant in itself since it occurs in the layer of the atmosphere where almost all daily human activities take place. Research has shown that heat islands have considerable implications for air quality (Rosenfeld et al., 1998; Sarrat et al., 2006; Davies et al., 2007), energy demand for cooling purposes (Santamouris et al., 2001; Konopacki and Akbari, 2002), human health (Conti et al., 2005; Haines et al., 2006), and regional/local atmospheric circulations (Lin et al., 2008; Miao et al., 2009). Further, although the UHI in itself does not influence global temperatures (Houghton et al., 2001), it does have an effect on local temperatures used for assessing climate change (Van Wevenberg et al., 2008).

According to the pioneering study of Oke (1982), heat islands develop as a result of the differences in the surface energy balance (SEB) between urban and rural areas. These differences are due to the combination of the thermal, radiative, aerodynamic and moisture properties of the urban fabric that significantly differ from those of the natural landscape (Oke, 
1987). Briefly, urban areas store more heat during the day than do rural areas, due to the generally lower surface albedo (Taha, 1997) and the surface enlargement provided by the canyon-like geometry (Christen and Vogt, 2004). Following sunset, the rural surroundings begin cooling quickly due to the generally unobstructed sky view. Meanwhile, the cooling rate of the urban environment is significantly reduced because of the decreased sky view factor and the increased release of storage heat from the urban surfaces (Grimmond and Oke, 1995). As a result, urban and rural temperatures begin to diverge, generating the UHI, until after sunrise the daily solar radiation cycle begins and the urban/rural areas start warming quickly. Therefore, the UHI is primarily a nocturnal phenomenon resulting from the diverging urban/rural cooling rates (Oke, 1982, 1987).

Numerical modeling is considered to be an appropriate tool for studying the UHI effect, showing a wide area of successful applications (Rizwan et al., 2009). In particular, meso-scale atmospheric models have been extensively used during the past decade for investigating heat islands. This has been made possible through the introduction of a new generation of urbanization schemes to meteorological models such as the Fifth-generation Pennsylvania State University - NCAR (National Centre for Atmospheric Research) Mesoscale Model (MM5) (Taha 1999; Taha and Bornstein, 1999, Dupont et al., 2004; Otte et al., 2004; Liu et al., 2006; Taha 2008a, b), Weather Research and Forecasting (WRF) model (Martilli et al., 2002; Kusaka and Kimura, 2004; Liu et al., 2006), UK Met Office operational model (Best, 2005), French Meso-NH model (Lemonsu and Masson, 2002), and NCAR global climate model (Olesson et al., 2008). However, the above urban parameterizations vary significantly in terms of the degrees of freedom used for treating urban processes and it is still not clear which degree of complexity of urban modeling should be incorporated into atmospheric models (Chen et al., 2011).

Properly designed modeling systems can be used as a powerful tool for detailed and continuous monitoring of the urban thermal environment. The implementation of such systems for investigating the UHI could provide valuable information to civil protection and urban planning authorities, but also to the general public. Up to now, this has been well documented in the scientific literature and numerous heat island modeling studies have been conducted in cities as diverse as Athens, Greece (Giannaros et al., 2013), Gothenborg, Sweden (Miao et al., 2007), Oklahoma City, USA (Liu et al., 2006), and Taipei, Taiwan (Lin et al., 2008).

The current paper presents the development of an urban modeling system, designed to support operational real-time weather forecasting activities. The modeling system exploits the capabilities of a state-of-the-art numerical weather prediction (NWP) model together with techniques for improving the representation of urban areas. The philosophy upon which it is built is the provision of reliable, high-resolution forecasting products, related to the heat island effect and hu- man thermal comfort. In this context, several new developments and modifications were carried out, aiming to improve the quality of the final products without increasing computational demands. The presented modeling system is practically designed to support applications over any urban area of the European continent. This study focuses on the operational implementation of the system for the city of Athens, Greece, during a 1.5-month period in the summer of 2010.

\section{Description of the study area}

Athens $\left(37^{\circ} 58 \mathrm{~N}, 23^{\circ} 43 \mathrm{E}\right)$ is the capital and largest city of Greece. It is located on a small peninsula situated in the south-eastern end of the Greek mainland (Fig. 1a). The greater Athens area (GAA) covers approximately $450 \mathrm{~km}^{2}$ and the urban zone sprawls across a basin that is often referred to as the Attica Basin. The city is surrounded by fairly high mountains to the west (Mount Aigaleo, $469 \mathrm{~m}$ ), north (Mount Parnitha, $1413 \mathrm{~m}$ ), northeast (Mount Penteli, $1109 \mathrm{~m}$ ) and east (Mount Hymettus, $1026 \mathrm{~m}$ ). Athens is also influenced by the sea to the south (Saronic Gulf). The industrial zone of the city is located in the western part of the Attica Basin (Thriassion Plain), while the Mesogeia Plain dominates in the southeast of the peninsula (Fig. 1b).

Athens enjoys a typical Mediterranean climate with hot, dry summers and cold, mild winters. The average daily maximum temperature in the summer months of July and August reaches approximately $32^{\circ} \mathrm{C}$, often exceeding $37^{\circ} \mathrm{C}$ when a heat wave occurs. The city also experiences a strong UHI effect as reported in several previous studies (e.g. Katsoulis and Theoharatos, 1995; Philandras et al., 1999; Santamouris et al., 2001; Keramitsoglou et al., 2011).

\section{Overview of the modeling system}

Figure 2 presents the flow chart of the modeling system (hereafter "the UHI-MS") that was developed for the operational simulation of the UHI effect. The modeling system consists of three major parts: (1) the meteorological WRF model, (2) the Noah land surface model (LSM), and (3) a statistical downscaling mask, developed to increase spatial resolution. The input of the UHI-MS involves static terrestrial data, such as topography and land use/cover, and land surface data, such as albedo and emissivity. The initialization can be carried out using data from a larger-scale atmospheric model, such as the Global Forecasting System (GFS) operated by the National Centre for Environmental Predictions (NCEP). The primary output of the UHI-MS consists of 3-day high-resolution forecasts for near-surface air temperature.

A detailed description of the various components, input/output data, and procedures of the UHI-MS is given in the following sections. 

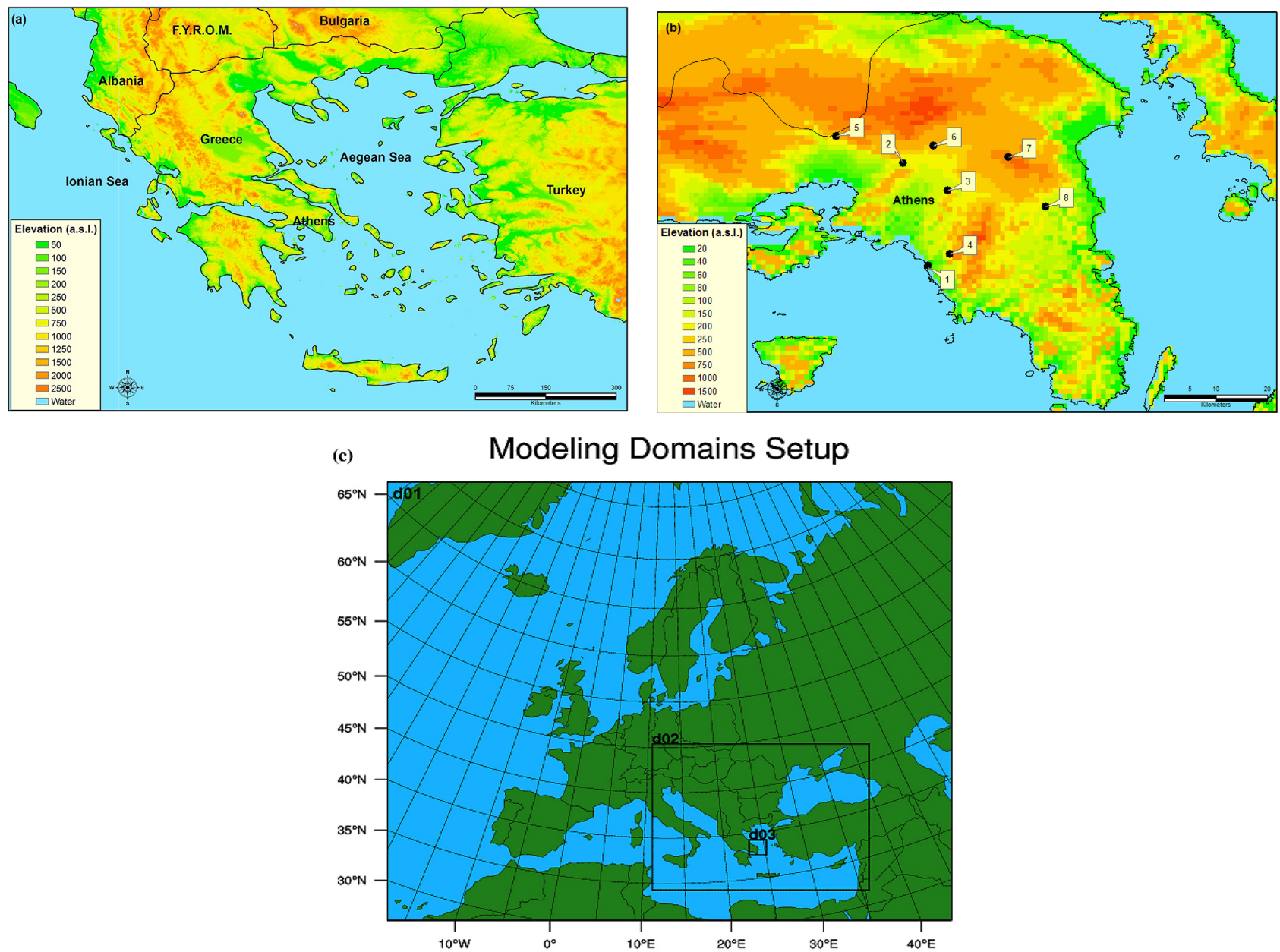

Fig. 1. Topography of (a) Greece, with identification of the city of Athens, and (b) GAA, with identification of the locations of the measurement sites. (c) Configuration of the three one-way nested domains used for the WRF simulations.

\subsection{The WRF/Noah modeling system}

As seen in Fig. 2, the meteorological driver of the UHI-MS is the WRF model, version 3.2 (Skamarock et al., 2008), coupled with the Noah LSM (Chen and Dudhia, 2001). The key advantage of this architecture lies in that it allows for a computationally efficient representation of the urban thermal environment. In particular, the coupled WRF/Noah modeling system includes a bulk urban parameterization that can be used for representing zero-order effects of urban surfaces (Liu et al., 2006). Within this simple urban scheme, urban areas are treated as homogenous surfaces whose radiative (albedo, emissivity), thermal (heat capacity, thermal conductivity) and other (roughness length, green vegetation fraction) properties are properly modified to account for the urban effects. This approach is considered to be suitable for operational forecasting applications, as highlighted in the study of Liu et al. (2006).

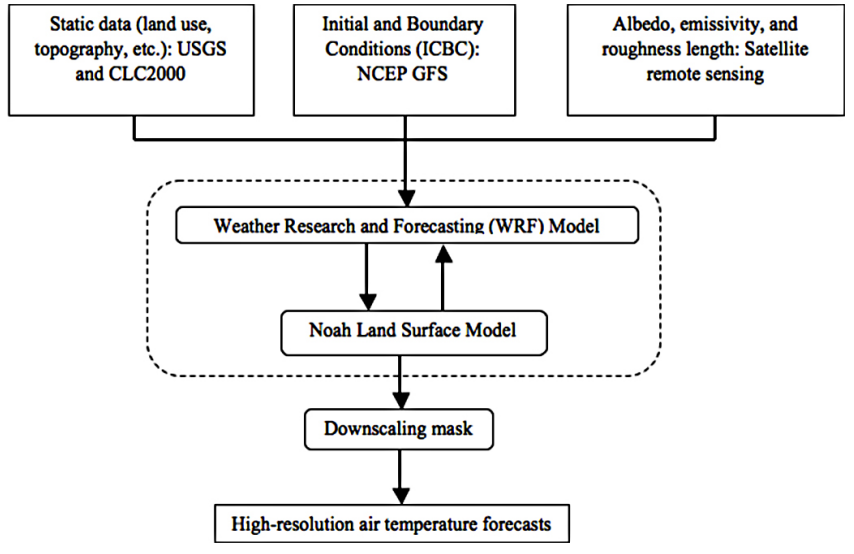

Fig. 2. Flow chart of the urban heat island modeling system. 


\subsubsection{Representation of urban land use}

The employment of the urbanization scheme of Liu et al. (2006) requires that land use be represented as accurately as possible. This is because the land surface parameters are specified in the WRF/Noah as a function of the land use category.

In the standard WRF configuration, land use can be represented using either the 24-category and 30 arcsec spatial resolution US Geological Survey (USGS) global land cover characteristics data set or the 20-category and 30 arcsec spatial resolution International Geosphere-Biosphere (IGBP) global land cover data set. Despite their relatively high horizontal resolution, which approximates $1 \mathrm{~km}$, both data sets are considered to be inadequate for urban modeling purposes. This is mainly because they include a single category for representing urban areas (Skamarock et al., 2008). Further, the USGS data set is considered to be outdated since it is derived from $1 \mathrm{~km}$ AVHRR (Advanced Very High Resolution Radiometer) data spanning from April 1992 through May 1993. Nevertheless, both data sets do provide an option for detailed urban land use representation, as long as such data are available.

To enable the detailed urban land use representation in the WRF/Noah modeling system, the $250 \mathrm{~m}$ spatial resolution European Environment Agency (EEA) CORINE (Coordination of Information on the Environment) land cover (CLC) data set, version 12/2009, was employed. As shown in Table 1, all urban elements of the CLC data set were first extracted and remapped to the corresponding IGBP land use categories. The remapped $250 \mathrm{~m}$ resolution CLC urban land use elements were then overlaid with the 30 arcsec resolution IGBP land use grid. Finally, each IGBP grid cell was assigned to the maximum percentage CLC urban land use category, as illustrated in Fig. 3.

At a second stage, the detailed urban land use information was exploited for specifying new values for the critical parameters of surface albedo and emissivity, and roughness length. These values were defined per CLC urban land use category using satellite remote sensing data collected in the frame of the "Urban Heat Islands and Urban Thermography" project (hereafter "the UHI project"), funded by the European Space Agency (ESA). The description of the methodology applied for deriving these parameters is beyond the scope of this paper, but it can be found in Viel et al. (2011). The satellite-retrieved surface albedo and emissivity, and roughness length values were corresponded to the IGBP urban land use categories by applying the mapping scheme presented in Table 1. For clarity, Table 2 highlights the values that were specified for the city of Athens, Greece.

\subsection{The downscaling mask}

Air temperature variations due to the UHI effect can be significant on the scale of a few hundreds of meters. There-

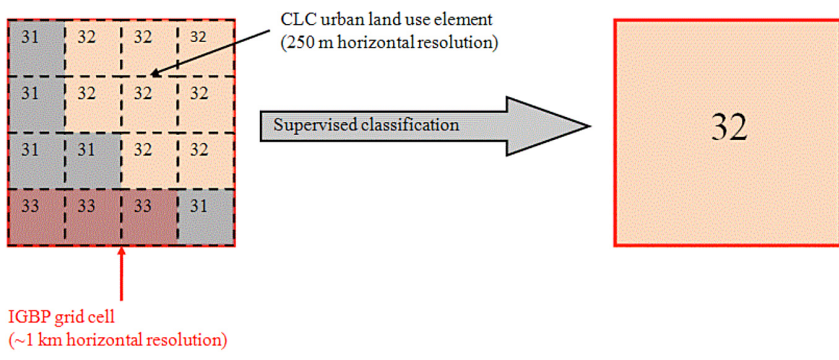

Fig. 3. Supervised classification and aggregation of the $250 \mathrm{~m}$ spatial resolution CLC urban land use elements to the 30 arcsec spatial resolution IGBP land use grid.

fore, the numerical simulation of heat islands requires in principle the adoption of a high horizontal grid resolution (e.g. $\leq 1 \mathrm{~km}$ ). However, this is not always possible because of limitations in the availability of computational resources. This is particularly true in operational forecasting systems, as the one presented herein, where forecasts should always be delivered on time. Within this context, downscaling techniques can provide an alternative solution for producing high-resolution forecasts without increasing computational demands.

In the present study, a downscaling mask was developed, exploiting the artificial neural network (ANN) technology. The principle idea was to design and train an ANN to predict air temperature at high spatial resolution. For this, the Tiberius Data Mining software (version 6.1.9, http://www. tiberius.biz/), a predictive modeling tool allowing for the design and implementation of ANNs, was selected for setting up a high-resolution temperature predictive neural network. The feed-forward architecture was chosen for designing the ANN, based on literature review and a preliminary trial and error procedure for various types of neural networks. In this case, all of the data information flows in one direction. The neurons of one layer are connected to the neurons of the following layer using adjustable weights and there is no feedback (Fig. 4). The initial weights of the neural network were randomly specified.

As seen in Fig. 4, the designed ANN consists of one hidden layer with seven neurons, followed by one output layer with a single neuron. The back propagation learning algorithm was used for training the network, while the tangent sigmoid function was used for transferring data from one layer to the other. The input layer consists of three neurons, responsible for feeding the ANN with the input data. The latter include: (1) the time of the day, transformed using the cosine function, to represent the diurnal cycle of air temperature, (2) the high-resolution CLC land use data to represent the effect of land surface type on air temperature, and (3) the WRF/Noah simulated air temperature data, bilinearly interpolated onto the locations of the measurement sites that were used during the training of the ANN. It should be noted that prior to the selection of the above proxy data, several other 
Table 1. Summary of the mapping scheme between the CLC urban land use elements and IGBP (WRF) urban land use categories.

\begin{tabular}{lll}
\hline CLC urban categories & Abbreviation & WRF urban categories \\
\hline 1.1.1. Continuous urban fabric & CUF & High intensity residential \\
1.1.2. Discontinuous urban fabric & DUF & Low intensity residential \\
1.2.1. Industrial commercial units & IOC & Industrial or commercial \\
1.2.2. Road/rail networks and associated land & URB & Urban and built-up \\
1.2.3. Port areas & URB & Urban and built-up \\
1.2.4. Airports & URB & Urban and built-up \\
1.3.1. Mineral extraction sites & URB & Urban and built-up \\
1.3.2. Dump sites & URB & Urban and built-up \\
1.3.3. Construction sites & URB & Urban and built-up \\
1.4.1. Green urban areas & DUF & Low intensity residential \\
1.4.2. Sport and leisure facilities & DUF & Low intensity residential \\
\hline
\end{tabular}

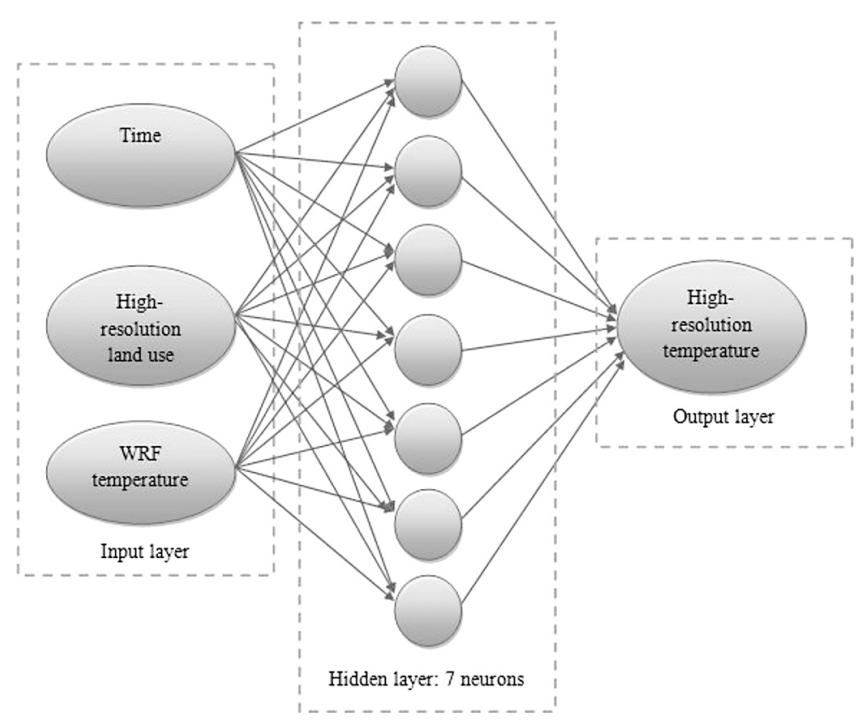

Fig. 4. Schematics diagram of the feed-forward neural network architecture.

combinations of input data were tested without inducing significant improvements on the network's performance.

The downscaling neural network was trained and tested for the city of Athens, Greece, during a one-month period in the summer of 2009. The training/testing methodology and the corresponding results are described in detail in Giannaros (2013). In brief, this procedure resulted in a statistical, nonlinear downscaling equation of the following form:

$\operatorname{AT}\left(i_{\mathrm{c}}\right)=f\left(\mathrm{LU}\left(i_{\mathrm{c}}\right), \mathrm{MAT}, \mathrm{h}\right)$,

where $\operatorname{AT}\left(i_{\mathrm{c}}\right)$ and $\operatorname{LU}\left(i_{\mathrm{c}}\right)$ are the air temperature and land use category of the $i_{\mathrm{c}}$ th CLC grid point, respectively, MAT is the model-simulated air temperature, bilinearly interpolated onto the location of the $i_{\mathrm{c}}$ th CLC grid point, and $\mathrm{h}$ is the time of the day, transformed using the cosine function. Eq. (1) is applied as a post-processing step after the implementation of the WRF/Noah modeling system (Fig. 2), resulting in an air
Table 2. Satellite-derived land surface parameters for the city of Athens, Greece, used in the WRF/Noah modeling system.

\begin{tabular}{lccc}
\hline WRF land use class & Albedo & $\begin{array}{r}\text { Emissivity } \\
\text { length (m) }\end{array}$ & $\begin{array}{c}\text { Rough- } \\
\text { ness }\end{array}$ \\
\hline High intensity residential & 0.11 & 0.97 & 1.080 \\
Low intensity residential & 0.09 & 0.97 & 0.600 \\
Industrial or commercial & 0.10 & 0.97 & 0.570 \\
Urban and built-up & 0.10 & 0.88 & 0.800 \\
\hline
\end{tabular}

temperature field whose spatial resolution equals that of the CLC grid (i.e. $250 \mathrm{~m}$ ).

\section{Numerical simulations and evaluation methods}

\subsection{Modeling system configuration}

The UHI-MS was implemented operationally during a 1.5month period in the summer of 2010, spanning from 13 July to 27 August 2010. Three one-way nested domains with horizontal grid resolutions of $30 \mathrm{~km}$ (d01; mesh size of $199 \times 175), 10 \mathrm{~km}(\mathrm{~d} 02$; mesh size of $214 \times 175)$, and $2 \mathrm{~km}$ (d03; mesh size of $75 \times 75$ ) were defined (Fig. 1c). The outermost $30 \mathrm{~km}$ domain covers most of the European continent and is used for simulating large-scale meteorological conditions. The inner two domains ( $\mathrm{d} 02$ and $\mathrm{d} 03$ ) are used for simulating meso-scale and local-scale meteorological patterns, of which the innermost domain (d03) focuses on the study area. All modeling domains have 33 layers in the vertical dimension. The lowest layer is found at approximately $10 \mathrm{~m}$ above ground level, while the model top is defined at $100 \mathrm{hPa}$ with radiative boundary conditions for all domains.

The WRF single-moment six-class scheme (WSM6) was used for the parameterization of microphysical processes (Hong et al., 2004). Longwave radiation processes were parameterized using the Eta Geophysical Fluid Dynamics Laboratory (GFDL) scheme (Schwarzkopf and Fels, 1991) while 
the MM5 scheme (Dudhia, 1989) was adopted for shortwave radiation. The MM5 similarity scheme (Zhang and Anthes, 1982) was selected for parameterizing the surface layer. Planetary boundary layer (PBL) processes were handled using the Yonsei University (YSU) scheme (Hong et al., 2006) and the Kain-Fritsch scheme (Kain, 2004) was used for parameterizing cumulus convection. Land surface processes were parameterized by coupling the WRF model with the Noah LSM (also refer to Sect. 3).

The numerical simulations were initialized on a daily basis using the operational $0.5^{\circ} \times 0.5^{\circ}$ spatial resolution and $6 \mathrm{~h}$ temporal resolution NCEP/GFS data. The lateral boundary conditions for the outermost modeling domain (d01) were obtained by linearly interpolating the 6-hourly NCEP/GFS data, while for the innermost domains (d02 and d03) the lateral boundary conditions were formed through interpolation from the parent domain (d01). Soil moisture and temperature data were also initialized from the NCEP/GFS data.

For the previously defined 1.5 -month period, $84 \mathrm{~h}$ numerical simulations were conducted operationally, on a daily basis, providing model output at $1 \mathrm{~h}$ intervals. The first $12 \mathrm{~h}$ of each simulation were discarded as the warm-up period of the model. The evaluation of the modeling system was conducted using the first $24 \mathrm{~h}$ of the remaining $72 \mathrm{~h}$ of each daily simulation.

\subsection{Evaluation methods}

The performance of the UHI-MS was evaluated using in situ data collected from a network of eight weather stations installed and operated in the GAA by the Hydrological Observatory of Athens (HOA) of the National and Technical University of Athens (NTUA). The locations of the stations are shown in Fig. 1b. Table 3 summarizes the main characteristics of the measurement sites.

The conducted evaluation focuses on the near-surface air temperature, defined at $2 \mathrm{~m}$ above ground level (a.g.l.) and thermal comfort conditions; the latter being described by two indices. For this, the downscaled $250 \mathrm{~m}$ resolution model results were first interpolated onto the locations of the measurement sites using bilinear interpolation. The interpolated forecast data were then compared with the observations. The statistical measures that were computed to quantitatively evaluate the performance of the modeling system include:

1. the mean bias error (MBE),

$$
\operatorname{MBE}=\frac{1}{N} \sum_{i=1}^{N}\left(f_{i}-o_{i}\right)
$$

and,

2. the root mean squared error (RMSE),

$$
\mathrm{RMSE}=\sqrt{\frac{1}{N-1} \sum_{i=1}^{N}\left(f_{i}-o_{i}\right)^{2},}
$$

where letters " $f$ " and " $o$ " denote modeled and observed data, respectively.

\section{Results}

\subsection{Near-surface air temperature}

Figure 5 presents a summary of the overall performance of the modeling system during the 2-month operational implementation. It can be seen that the UHI-MS tends to overestimate near-surface air temperature, showing a warm bias on approximately $60 \%$ of the examined cases. Nevertheless, model errors are found to rarely exceed $3 \mathrm{~K}$, while the majority of them $(\sim 80 \%)$ lies in between -2 and $2 \mathrm{~K}$. This results in a low MBE of $0.45 \mathrm{~K}$ and a RMSE that is lower than $2 \mathrm{~K}$ (Fig. 5a). The highest MBE values are found for the DUF and URB sites, although not exceeding $1 \mathrm{~K}(0.91$ and $0.81 \mathrm{~K}$, respectively). On the other hand, the computed RMSE values show little variation, ranging from $1.43 \mathrm{~K}$ (IOC) to $1.99 \mathrm{~K}$ (DUF). Putting this information together, it can be claimed that, overall, the UHI-MS performs well in simulating the near-surface air temperature field over the study area.

Figure 6 shows the time series of observed and modeled daily mean, maximum and minimum near-surface air temperature, averaged over all measurement sites. The UHI-MS is found to simulate well the day-to-day variations of temperature during the entire study period. In particular, it captures successfully the prolonged period of high temperatures, from 13 to 20 August 2010 (observed and modeled daily mean temperatures exceeding $30^{\circ} \mathrm{C}$ ), as well as the abrupt cooling of the study area on 21 August 2010 (Fig. 6a). It is also evident that maximum temperatures are generally underestimated by approximately $1.0-1.5 \mathrm{~K}$ (Fig. 6b), whereas minimum temperatures are systematically overestimated by about 1.5-2 K (Fig. 6c).

The UHI-MS is also found to perform well on the average diurnal course (Fig. 7). The excess warmth of the urbanized sites (Fig. 7a-c) relative to the rural ones (Fig. 7d), indicating the existence of the UHI, is generally simulated well. The timing of observed and modeled temperature minima and maxima also coincide well. The modeling system captures successfully the magnitude of the average daily maximum temperature, showing absolute errors that do not exceed $1 \mathrm{~K}$. On the other hand, the errors of the modeled average daily minimum temperature are generally larger, exceeding $2 \mathrm{~K}$ in the case of DUF sites (Fig. 7a). In general, it can be seen that the UHI-MS performs better during the daytime (07:00-20:00 LT, LT = UTC + 3), than during the night (21:00-06:00 LT). Indeed, daytime model errors vary, on average, from $-0.46 \mathrm{~K}$ (IOC, Fig. 7b) to $0.56 \mathrm{~K}$ (URB, Fig. 7c). During the night, the respective values lie in between $0.08 \mathrm{~K}$ (RUR, Fig. 7d) and $1.98 \mathrm{~K}$ (DUF, Fig. 7a), indicating that nighttime temperatures are overestimated. Looking at Fig. 7, one can finally notice that the modeling system performs 
Table 3. Characteristics of the measurement sites used for the evaluation of the modeling system.

\begin{tabular}{llccccc}
\hline ID & $\begin{array}{l}\text { Area } \\
\text { name }\end{array}$ & $\begin{array}{c}\text { Latitude } \\
\left({ }^{\circ} \mathrm{N}\right)\end{array}$ & $\begin{array}{c}\text { Longitude } \\
\left({ }^{\circ} \mathrm{E}\right)\end{array}$ & $\begin{array}{c}\text { Altitude } \\
\left(\mathrm{m} \text { a.s.1. } .^{\mathrm{a}}\right)\end{array}$ & $\begin{array}{c}\text { Sampling } \\
\text { height } \\
\left(\mathrm{m} \text { a.g.l. }{ }^{\mathrm{b}}\right)\end{array}$ & $\begin{array}{c}\text { Land } \\
\text { cover } \\
\text { type }^{\mathrm{c}}\end{array}$ \\
\hline 1 & Helliniko & $37^{\circ} 53^{\prime} 56^{\prime \prime}$ & $23^{\circ} 43^{\prime} 24^{\prime \prime}$ & 6 & 2 & URB \\
2 & Ano Liosia & $38^{\circ} 4^{\prime} 36^{\prime \prime}$ & $23^{\circ} 40^{\prime} 50^{\prime \prime}$ & 184 & 2 & IOC \\
3 & Galatsi & $38^{\circ} 1^{\prime} 46^{\prime \prime}$ & $23^{\circ} 45^{\prime} 28^{\prime \prime}$ & 176 & 2 & URB \\
4 & Ilioupoli & $37^{\circ} 55^{\prime} 6^{\prime \prime}$ & $23^{\circ} 45^{\prime} 40^{\prime \prime}$ & 206 & 2 & DUF \\
5 & Mandra & $38^{\circ} 7^{\prime} 22^{\prime \prime}$ & $23^{\circ} 33^{\prime} 49^{\prime \prime}$ & 258 & 2 & RUR \\
6 & Menidi & $38^{\circ} 6^{\prime} 24^{\prime \prime}$ & $23^{\circ} 44^{\prime} 2^{\prime \prime}$ & 210 & 2 & DUF \\
7 & Penteli-2 & $38^{\circ} 5^{\prime} 11^{\prime \prime}$ & $23^{\circ} 51^{\prime} 49^{\prime \prime}$ & 729 & 2 & RUR \\
8 & Pikermi & $38^{\circ} 0^{\prime} 4^{\prime \prime}$ & $23^{\circ} 55^{\prime} 43^{\prime \prime}$ & 133 & 2 & RUR \\
\hline
\end{tabular}

${ }^{a}$ Above sea level. ${ }^{b}$ Above ground level. ${ }^{c}$ Land cover type as derived from the modeling system (see Table 1; RUR: rural).

(a)

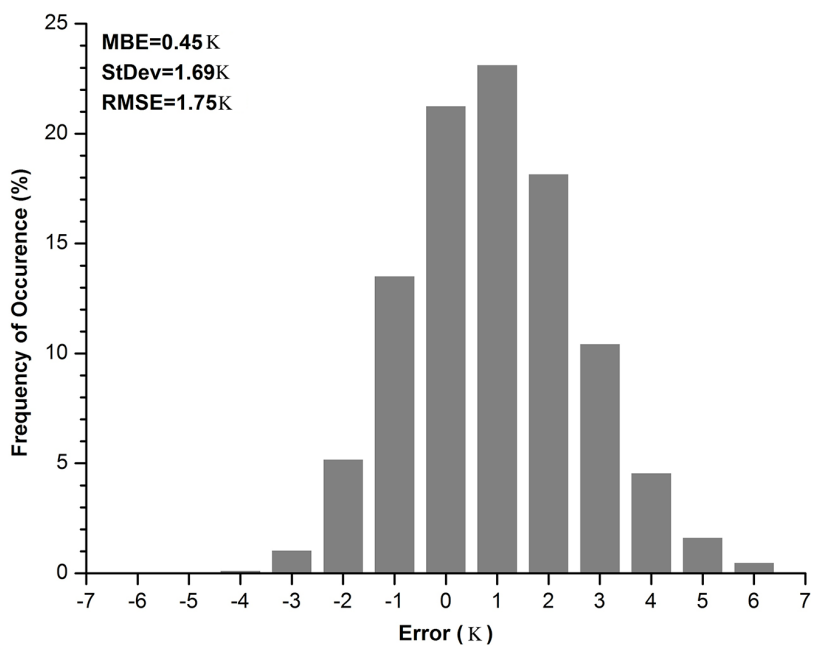

(b)

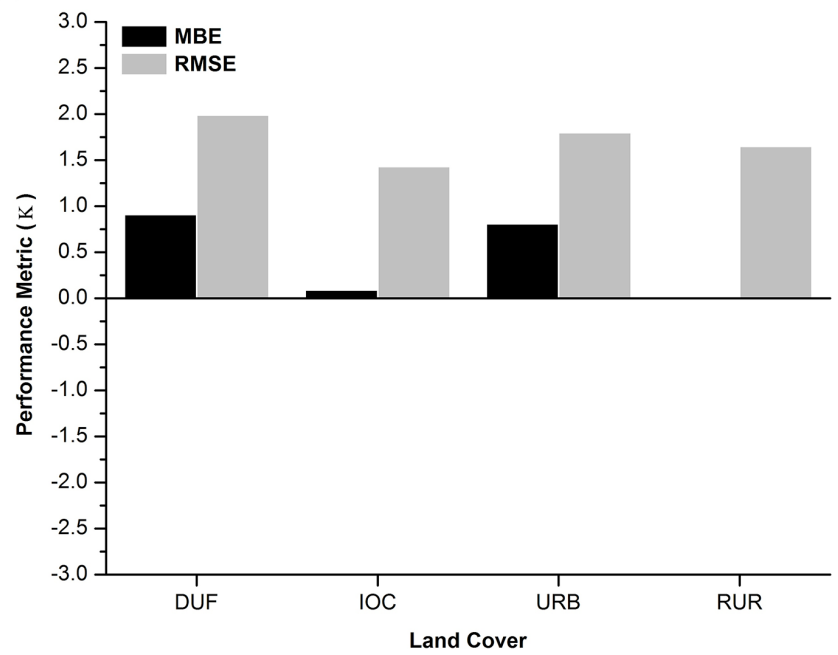

Fig. 5. (a) Distribution of errors in the modeled near-surface air temperature, and (b) model performance metrics (MBE, RMSE) for the near-surface air temperature, grouped by land use category. remarkably better over the RUR sites (Fig. 7d) than over the urbanized land cover types (Figs. 7a-c).

\subsection{Thermal comfort}

When high temperatures are combined with low wind speeds and high humidity, the population may be put under severe thermal stress. The deterioration of human thermal comfort conditions in urban areas is a well-known and documented problem, potentially associated with the UHI effect (e.g. Giannaros and Melas, 2012; Poupkou et al., 2011). Accurate forecasting of urban thermal comfort conditions is thus critical for limiting the adverse impacts of heat waves and heat islands on human health. Such forecasts could be used for both informing the inhabitants of a city and developing successful short-term mitigation strategies.

In the present study, the ability of the UHI-MS to simulate/forecast thermal comfort conditions over the study area is evaluated using two biometeorological indices: (a) the discomfort index (DI), and (b) the approximated wet-bulb globe temperature (AWBGT). Both indices fall into the category of the so-called "simple" indices, since they do not account for the human thermal physiology. In particular, they only consider the effects of air temperature and humidity, neglecting other more important variables such as the mean radiant temperature or wind speed. In a sense, they could be considered to be inadequate for describing human thermal comfort since they are not physiologically significant. However, they have been selected in this study since they can be easily validated, given the available observational data.

DI, originally proposed by Thom (1959), is a simple and widely used index of thermal comfort. It can be computed using Eq. (4) by Giles et al. (1990):

$\mathrm{DI}=T_{\mathrm{a}}-0.55 \cdot(1-0.01 \cdot \mathrm{RH}) \cdot\left(T_{\mathrm{a}}-14.5\right)$,

where $T_{\mathrm{a}}$ is the air temperature $\left({ }^{\circ} \mathrm{C}\right)$ and $\mathrm{RH}$ the relative humidity (\%). DI values below or equal to $21^{\circ} \mathrm{C}$ $\left(\mathrm{DI} \leq 21^{\circ} \mathrm{C}\right.$ ) correspond to absence of thermal discomfort. 
(a)

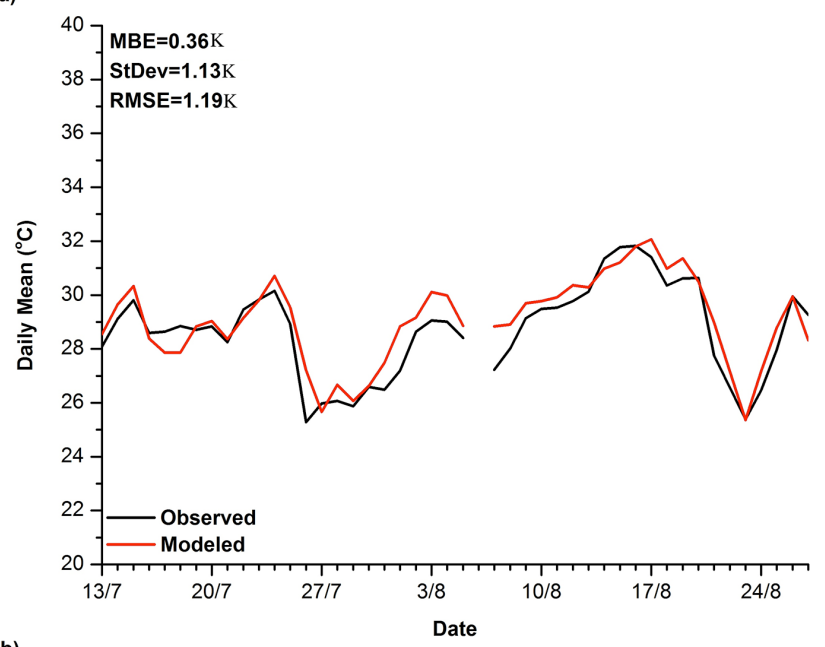

(b)

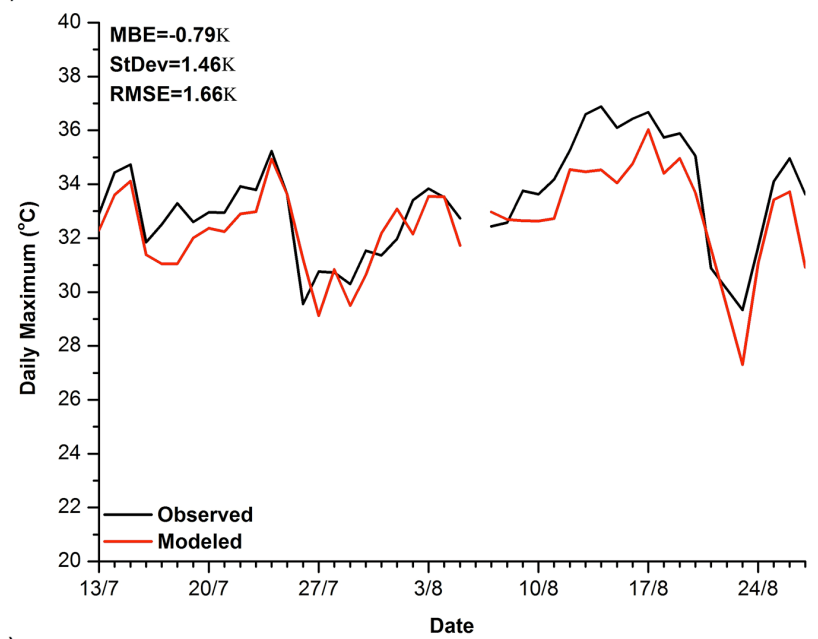

(c)

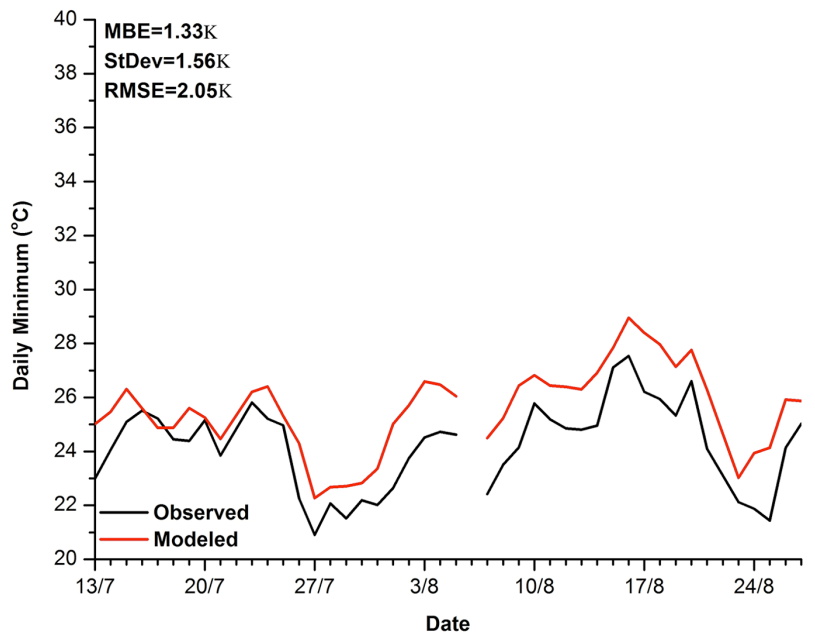

Fig. 6. Observed (black solid line) and modeled (red solid line) time series of the daily (a) mean, (b) maximum, and (c) minimum near-surface air temperature, averaged over all measurement sites. Statistical parameters are presented within the plots (MBE, RMSE, StDev: Standard Deviation).
When $21^{\circ} \mathrm{C}<\mathrm{DI} \leq 24^{\circ} \mathrm{C}$ less than half the population is expected to feel discomfort, while when $24^{\circ} \mathrm{C}<\mathrm{DI} \leq 27^{\circ} \mathrm{C}$ the percentage of the population feeling discomfort rises to $50 \%$. The majority of the population is anticipated to feel discomfort when $27^{\circ} \mathrm{C}<\mathrm{DI} \leq 29^{\circ} \mathrm{C}$, and the entire population is feeling discomfort when $29^{\circ} \mathrm{C}<\mathrm{DI} \leq 32^{\circ} \mathrm{C}$. DI values exceeding $32^{\circ} \mathrm{C}\left(\mathrm{DI}>32^{\circ} \mathrm{C}\right)$ correspond to sanitary emergency conditions.

AWBGT is an index that can be used for evaluating outdoor thermal stress conditions. It can be computed using Eq. (5) (Steeneveld et al., 2011):

$\mathrm{AWBGT}=0.567 \cdot T_{\mathrm{a}}+0.393 \cdot e+3.94$,

where $e$ is the water vapor pressure (hPa). Contrary to DI, the threshold values of AWBGT depend largely on personal clothing and level of activity. Nevertheless, the computed AWBGT values can be interpreted using a more general classification scheme as proposed by Steeneveld et al. (2011). AWBGT values lower than $27.7^{\circ} \mathrm{C}$ (AWBGT $<27.7^{\circ} \mathrm{C}$ ) represent absence of heat stress conditions. For $27.7^{\circ} \mathrm{C}<$ AWBGT $<32.2^{\circ} \mathrm{C}$ heat stress increases, while for AWBGT $>32.2^{\circ} \mathrm{C}$ great heat stress danger occurs.

Observed and modeled hourly DI and AWBGT values were computed applying Eqs. (4) and (5), respectively. The water vapor pressure data $(e)$, needed for the calculation of AWBGT, were derived using the air temperature and relative humidity data. First, the saturation vapor pressure was estimated, applying the Goff-Gratch equation (WMO, 2000); the vapor pressure was subsequently computed using the observed and modeled relative humidity.

Figure 8 presents the time series of observed and modeled DI and AWBGT, averaged over all measurement sites. Clearly, the UHI-MS reproduces successfully the phase of the diurnal cycle of both indices, as well as the day-to-day variations. For instance, it can be seen that it captures the low DI and AWBGT values during the period from 27 to 31 July 2010. The increased values during the period from 17 to 20 August 2010 are also well reproduced. However, it can be noted that the modeling system performs better in simulating maximum DI and AWBGT values, but overestimates the minimum values of both indices. This can be attributed to the overestimation of nighttime minimum temperatures, as previously discussed (Sect. 5.1). This overestimation is found to be larger in the case of AWBGT (Fig. 8b), resulting in larger MBE and RMSE values than for DI (Fig. 8a).

Tables 4 and 5 present the frequency distributions of the observed and modeled hourly DI and AWBGT values, respectively, within the specified ranges, as a function of the land cover category. It is clear that the UHI-MS underestimates the occurrences of the lowest DI (Table 4) and AWBGT (Table 5) values, but simulates well the highest ones. As seen in Table 4, the occurrences of DI values in the third class $((24,27])$ are systematically overestimated; the overestimation being greater for the DUF and URB sites. On the other hand, the frequencies of the fourth DI class $((27,29])$ 
(a)

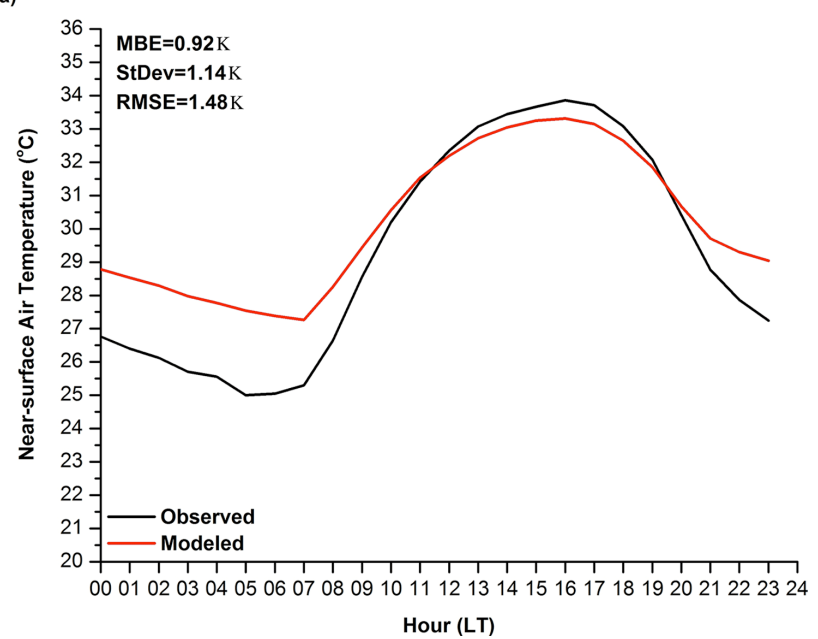

(c)

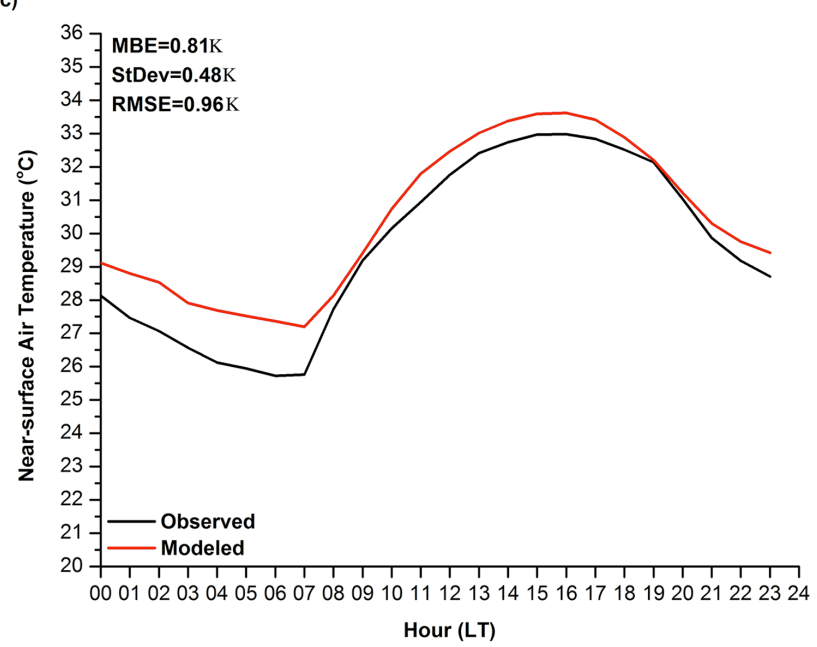

(b)

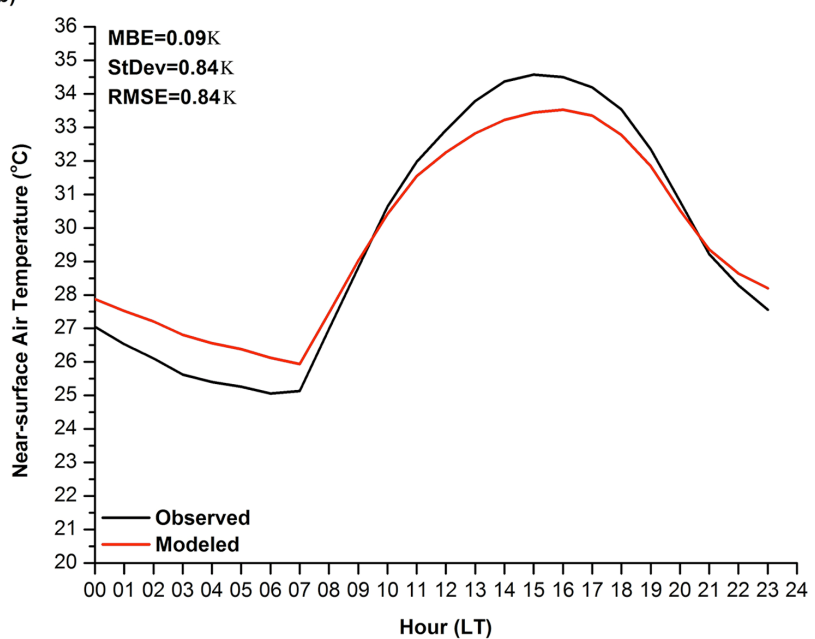

(d)

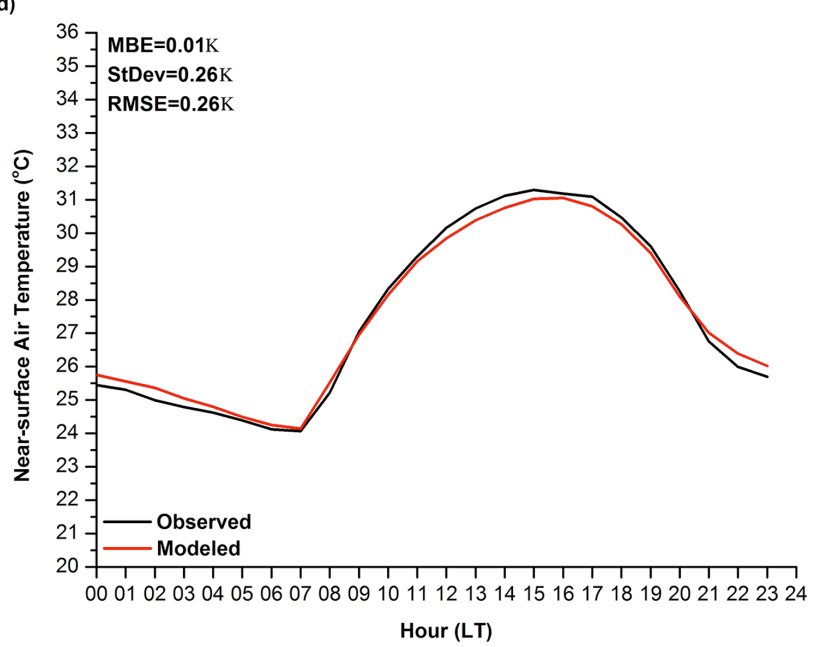

Fig. 7. Diurnal course of the near-surface air temperature averaged from 00:00 UTC 13 July to 23:00 UTC 27 August 2010 for (a) DUF, (b) IOC, (c) URB, and (d) RUR sites. Statistical parameters are presented within the plots (MBE, RMSE, StDev: Standard Deviation).

are, more or less, successfully reproduced over all land cover categories. The model-observations agreement as regards the variation of the occurrences of DI ranges among the different land cover categories is also found to be good. In particular, DUF and URB sites exhibit the highest observed and modeled frequencies for DI $>24^{\circ} \mathrm{C}$, while RUR sites show the highest observed and modeled frequencies for $\mathrm{DI} \leq 24^{\circ} \mathrm{C}$.

As for AWBGT (Table 5), the modeling system shows good skill in simulating values in the third class $\left(>32.2^{\circ} \mathrm{C}\right)$. The occurrences of AWBGT values in the second class ([27.7, 32.2]) are generally overestimated; the overestimation being again larger for the DUF sites. Nevertheless, the UHI-MS manages to reproduce adequately well the differences between the examined land cover categories. Most occurrences of AWBGT $<27.7^{\circ} \mathrm{C}$ are successfully modeled for the RUR sites, contrary to DUF and URB sites that both exhibit most occurrences of observed and modeled AWBGT $>32.2^{\circ} \mathrm{C}$.

\section{Conclusions}

The development of a heat island modeling system, which could be used in the context of operational real-time weather forecasting applications, is presented in the current paper. The performance of the modeling system is evaluated for a 1.5 -month period in the summer of 2010 , when it was implemented operationally, on a daily basis, for the city of Athens, Greece. The evaluation procedure focuses on the near-surface air temperature, which is the variable that is directly influenced by the UHI effect. In addition, the ability of the modeling system in terms of simulating thermal comfort conditions is evaluated, using two appropriate indices. 
(a)

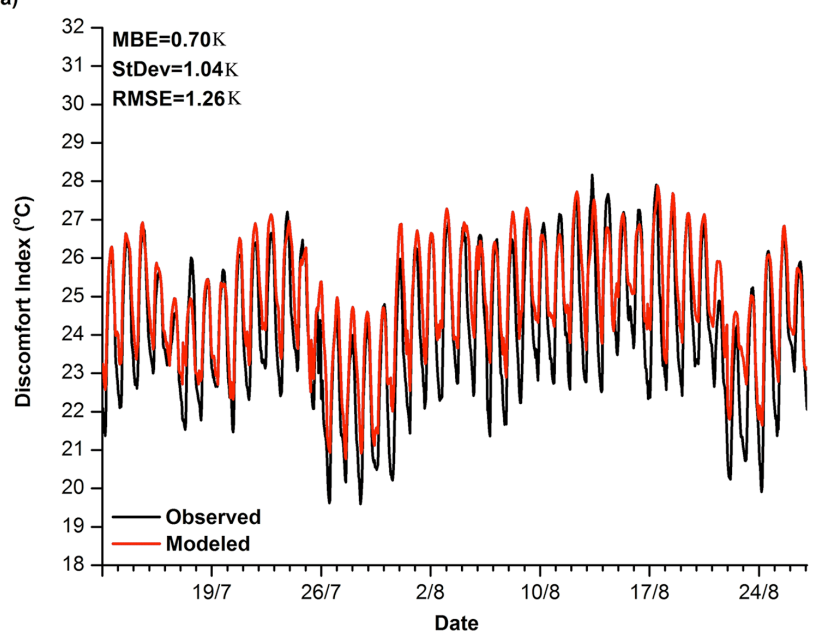

(b)

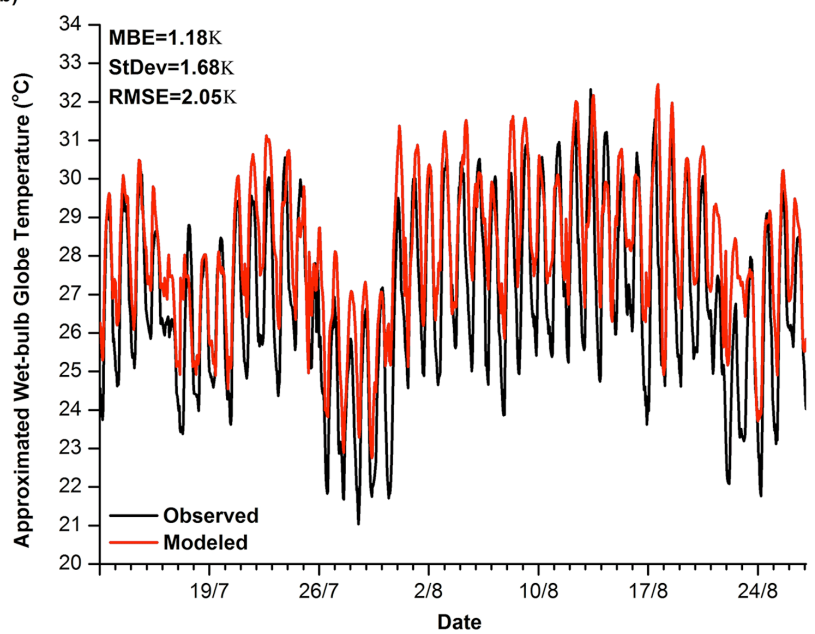

Fig. 8. Time series of observed (black solid line) and modeled (red solid line) (a) discomfort index, and (b) approximated wet-bulb globe temperature, averaged over all measurement sites. Statistical parameters are presented within the plots (MBE, RMSE, StDev: Standard Deviation).

Table 4. Frequency distributions (\%) of observed and modeled hourly DI values within the specified ranges, grouped by land use category.

\begin{tabular}{lrrrrrrrr}
\hline & \multicolumn{8}{c}{ Land use category } \\
\cline { 2 - 10 } DI & \multicolumn{2}{c}{ DUF } & \multicolumn{2}{c}{ IOC } & \multicolumn{2}{c}{ URB } & \multicolumn{2}{c}{ RUR } \\
\cline { 2 - 10 }$\left({ }^{\circ} \mathrm{C}\right)$ & Obs & Mod & Obs & Mod & Obs & Mod & Obs & Mod \\
\hline$\leq 21$ & 4.55 & 0.00 & 3.88 & 0.28 & 1.42 & 0.14 & 15.40 & 5.52 \\
$(21,24]$ & 36.74 & 10.09 & 36.74 & 27.18 & 21.83 & 17.80 & 50.09 & 42.77 \\
$(24,27]$ & 46.45 & 72.96 & 48.01 & 64.96 & 58.76 & 68.42 & 32.92 & 49.78 \\
$(27,29]$ & 12.22 & 16.95 & 11.36 & 7.58 & 17.61 & 13.64 & 1.58 & 1.93 \\
$(29,32]$ & 0.05 & 0.00 & 0.00 & 0.00 & 0.38 & 0.00 & 0.00 & 0.00 \\
$>32$ & 0.00 & 0.00 & 0.00 & 0.00 & 0.00 & 0.00 & 0.00 & 0.00 \\
\hline
\end{tabular}

Table 5. Same as Table 4, but for AWBGT.

\begin{tabular}{lrrrrrrrr}
\hline & \multicolumn{8}{c}{ Land use category } \\
\cline { 2 - 10 } AWBGT & \multicolumn{2}{c}{ DUF } & \multicolumn{2}{c}{ IOC } & \multicolumn{2}{c}{ URB } & \multicolumn{2}{c}{ RUR } \\
\cline { 2 - 10 }$\left({ }^{\circ} \mathrm{C}\right)$ & Obs & Mod & Obs & Mod & Obs & Mod & Obs & Mod \\
\hline$<27.7$ & 56.16 & 20.60 & 55.68 & 44.13 & 34.75 & 32.91 & 81.25 & 60.61 \\
{$[27.7,32.2]$} & 42.76 & 75.62 & 44.13 & 55.49 & 58.81 & 65.06 & 18.75 & 39.30 \\
$>32.2$ & 1.09 & 3.79 & 0.19 & 0.38 & 6.44 & 2.04 & 0.00 & 0.09 \\
\hline
\end{tabular}

Comparisons made with observations revealed an overall satisfactory performance of the modeling system. The following points summarize the findings of this study:

1. The modeling system simulates well the near-surface air temperature field over the study area, showing MBE and RMSE values of 0.45 and $1.75 \mathrm{~K}$, respectively. Among the different land cover types, model performance metrics show little variation.
2. Daily maximum temperatures are more accurately modeled, exhibiting a cold bias that does not exceed $1.5 \mathrm{~K}$. On the other hand, the cold bias of daily minimum temperatures is found to be larger, ranging from 1.5 to $2.0 \mathrm{~K}$.

3. On the average diurnal course, the modeling system is found to perform better during the day than during the night. 
4. The modeling system appears to be more able to capture the highest values of the examined thermal comfort indices, rather than the lowest ones.

5. The observed and modeled frequencies of occurrences for the various thermal comfort and heat stress classes agree reasonably well. This is particularly clear in the case of the classes representing more thermally deteriorated conditions.

In summary, our results indicate that given the necessary modifications and adaptations, meso-scale meteorological models constitute a promising tool for the operational simulation/forecasting of the urban thermal climate and thermal comfort conditions. Nevertheless, there is still room for improvement of the presented modeling system. For this, the model performance should be further evaluated, focusing explicitly on the heat island effect and its spatial and temporal variations. This remains to be carried out in the future, together with testing the modeling system over another urban area.

Acknowledgements. The presented work was conducted in the frame of the "Urban Heat Islands and Urban Thermography" project, funded by the European Space Agency (ESA) (Contract No. $21913 / 08 / \mathrm{I}-\mathrm{LG})$. The authors would also like to thank the two reviewers for their insightful comments.

Edited by: P. Nastos

Reviewed by: D. E. Syrakov and D. Scherer

\section{References}

Best, M. J.: Representing urban areas within operational numerical weather prediction models, Bound.-Lay. Meteorol., 114, 91-109, 2005.

Chen, F. and Dudhia, J.: Coupling and advanced land surfacehydrology model with the Penn State NCAR MM5 modeling system. Part I: Model implementation and sensitivity, Mon. Weather Rev., 129, 569-585, 2001.

Chen, F., Kusaka, H., Bornstein, R., Ching, J, Grimmond, C. S. B., Grossman-Clarke, S., Loridan, T., Manning, K. W., Martilli, A., Miao, S., Sailor, D., Salamanca, F. P., Taha, H., Tewari, M., Wang, X., Wyszogrodzki, A. A., and Zhang, C.: The integrated WRF/urban modeling system: development, evaluation, and applications to urban environmental problems, Int. J. Climatol., 31, 273-288, 2011.

Christen, A. and Vogt, R.: Energy and radiation balance of a central European city, Int. J. Climatol., 24, 1395-1421, 2004.

Conti, S., Meli, P., Mineli, G., Solimini, R., Toccaceli, V., Vichi, M., Beltrano, C., and Perini, L.: Epidemiologic study of mortality during the summer 2003 heat wave in Italy, Environ. Res. 98, 390-399, 2005.

Davies, F., Middleton, D. R., and Bozier, K. E.: Urban air pollution and measurements of boundary layer height, Atmos. Environ., 41, 4040-4049, 2007.
Dudhia, J.: Numerical study of convection observed during the winter monsoon experiment using a mesoscale two-dimensional model, J. Atmos. Sci., 46, 3077-3107, 1989.

Dupont, S., Otte, T. L., and Ching, J. K. S.: Simulation of meteorological fields within and above urban and rural canopies with a mesoscale model (MM5), Bound.-Lay. Meteorol., 113, 111-158, 2004.

Giannaros, T. M.: Study of the urban heat island effect using a mesoscale atmospheric model and analyzing observational data, Doctoral Dissertation, Aristotle University of Thessaloniki, 2013.

Giannaros, T. M. and Melas, D.: Study of the urban heat island in a coastal Mediterranean city: The case study of Thessaloniki, Greece, Atmos. Res., 118, 103-120, 2012.

Giles, B. D., Balafoutis, C. H., and Maheras, P.: Too hot for comfort: the heatwaves in Greece in 1987 and 1988, Int. J. Biometeorol., 34, 98-104, 1990.

Grimmond, C. S. B. and Oke, T. R.: Comparison of heat fluxes from summertime observations in the suburbs of four North American cities, J. Appl. Meteorol., 34, 873-889, 1995.

Haines, M. D., Kovats, R. S., Cambell-Lendrum, D., and Corvalan, C.: Climate change and human health: Impacts, vulnerability and mitigation, The Lancet, 367, 2101-2109, 2006.

Hong, S. Y. and Lim, J. O. J.. The WRF single-moment 6-class microphysics scheme (WSM6), J. Korean Meteor. Soc., 42, 129151, 2004.

Hong, S. Y., Noh, Y., and Dudhia, J.: A new vertical diffusion package with an explicit treatment of entrainment processes, Mon Weather. Rev., 134, 2318-2341, 2006.

Houghton, J. T., Ding, Y., Griggs, D. J., Noguer, M., van der Linden, P. J., Dai, X., Mashell, K., and Johnson, C. (Eds.): Climate change 2001: the scientific basis. Cambridge University Press, Cambridge, 881 pp., 2001.

Kain, J. S.: The Kain-Fritsch convective parameterization: An update, J. Appl. Meteorol., 43, 170-181, 2004.

Katsoulis, B. D. and Theoharatos, G. A.: Indications of the urban heat island in Athens, Greece, J. Climatol. Appl. Meteorol., 24, 1296-1301, 1995.

Keramitsoglou, I., Kiranoudis, C. T., Ceriola, G., Weng, Q., and Rajasekar, U.: Identification and analysis of urban surface temperature patterns in Greater Athens, Greece, using MODIS imagery, Remote Sens. Environ., 115, 3080-3090, 2011.

Konopacki, S. and Akbari, H.: Energy savings for heat island reduction strategies in Chicago and Houston (including updates for Baton Rouge, Sacramento, and Salt Lake City), Draft Final Report, LBNL-49638, University of California, Berkeley, 2002.

Kusaka, H. and Kimura, F.: Coupling a single-layer urban canopy model with a simple atmospheric model: impact on urban heat island simulation for an idealized case, J. Meteorol. Soc. Japan, 82, 67-80, 2004.

Lemonsu, A. and Masson, V.: Simulation of a summer urban breeze over Paris, Bound.-Lay. Meteorol., 104, 463-490, 2002.

Lin, C. H., Chen, F., Huang, J. C., Chen, W. C., Liou, Y. A., Chen, W. N., and Liu, S. C.: Urban heat island effect and its impact on boundary layer development and land-sea circulation over northern Taiwan, Atmos. Environ., 42, 5635-5649, 2008.

Liu, Y., Chen, F., Warner, T., and Bassara, J.: Verification of a mesoscale data-assimilation and forecasting system for the Oklahoma City area during the Joint Urban 2003 field project, J. Appl. Meteorol. Climatol., 45, 912-929, 2006. 
Martilli, A., Clappier, A., and Rotach, M. W.: An urban surface exchange parameterization for mesoscale models, Boundary-layer Meteorol., 104, 261-304, 2002.

Miao, J. F., Chen, D., and Borne, K.: Evaluation and comparison of Noah and Pleim-Xiu land surface models in MM5 using GOTE2001 data: Spatial and temporal variations in near-surface air temperature, J. Appl. Meteorol. Climatol., 46, 1587-1605, 2007.

Miao, S., Chen, F., Lemone, M. A., Tewari, M., Li, Q., and Wang, Y.: An observational and modeling study of the characteristics of urban heat island and boundary layer structures in Beijing, J. Appl. Meteorol. Climatol., 48, 484-501, 2009.

Oke, T. R.: The energetic basis of the urban heat island, Q. J. Roy. Meteor. Soc., 108, 1-24, 1982.

Oke, T. R.: Boundary layer climates, Methuen and Co., New York, 1987.

Olesson, K. W., Bonan, G. B., Feddema, J., Vertenstein, M., and Grimmond, C. S. B.: An urban parameterization for a global climate model: 1. Formulation \& evaluation for two cities, J. Appl. Meteorol. Climatol., 47, 1038-1060, 2008.

Otte, T. L., Lacser A., Dupont, S., and Ching, J. K. S.: Implementation of an urban canopy parameterization in a mesoscale meteorological model, J. Appl. Meteorol., 43, 1648-1665, 2004.

Philandras, C. M., Metaxas, D. A., and Nastos, P. Th.: Climate variability and urbanization in Athens, Theor. Appl. Climatol., 63, 65-72, 1999.

Poupkou, A., Nastos, P., Melas, D., and Zerefos, C.: Climatology of discomfort index and air quality index in a large urban Mediterranean agglomeration, Water Air Soil Pollut., 222, 163183, 2011.

Rizwan, A. M., Dennis, Y. C. L., and Liu, C.: A review on the generation, determination and mitigation of urban heat island, J. Environ. Sci., 20, 120-128, 2009.

Rosenfeld, A. H., Akbari, H., Romn, J. J., and Pomerantz, M.: Cool communities: strategies for heat island mitigation and smog reduction, Energ. Buildings, 28, 51-62, 1998.

Santamouris, M., Papanikolaou, N., Livada, I., Koronakis, I., Georgakis, C., and Assimakopoulos, D. N.: On the impact of urban climate to the energy consumption of buildings, Sol. Energy, 70, 201-216, 2001.

Sarrat, C., Lemonsu, A., Masson, V., and Guedalia, D.: Impact of urban heat island on regional atmospheric pollution, Atmos. Environ., 40, 1743-1758, 2006.
Schwarzkopf, M. D. and Fels, S. B.: The simplified exchange method revisited - An accurate, rapid method for computation of infrared cooling rates and fluxes, J. Geophys. Res., 96, 90759096, 1991.

Skamarock, W. C., Klemp, J. B., Dudhia, J., Gill, D. O., Barker, D. M., Duda, M. G., Huang, X. Y., Wang, W., and Powers, J. G.: A description of the advanced research WRF version 3, NCAR Technical Note (NCAR/TN-475+STR), Boulder, Colorado, USA, 2008.

Steeneveld, G. J., Koopmans, S., Heusinkveld, B. G., van Howe, L. W. A., and Holtslag, A. A. M.: Quantifying urban heat island effects and human comfort for cities of variable size and urban morphology in the Netherlands, J. Geophys. Res., 117, D20129, doi:10.1029/2011JD015988, 2011.

Taha, H.: Modeling the impacts of large-scale albedo changes on ozone air quality in the South Coast air basin, Atmos. Environ., 31, 1667-1676, 1997.

Taha, H.: Modifying a mesoscale meteorological model to better incorporate urban heat storage: a bulk-parameterization approach, J. Appl. Meteorol., 38, 466-473, 1999.

Taha, H.: Urban surface modification as a potential ozone air-quality improvement strategy in California: a mesoscale modeling study, Bound.-Lay. Meterol., 127, 219-239, 2008a.

Taha, H.: Meso-urban meteorological and photochemical modeling of heat island mitigation, Atmos. Environ., 42, 8795-8809, 2008b.

Taha, H. and Bornstein, R.: Urbanization of meteorological models: implications on simulated heat islands and air quality, International Congress on Biometeorology and International Conference on Urban Climatology (ICB-ICUC), Sydney, Australia, 8-12 November, 1999.

Thom, E. C.: The discomfort index, Weatherwise, 12, 57-60, 1959.

Van Wevenberg, K., De Ridder, K., and Van Rompaey, A.: Modeling the contribution of the Brussels heat island to a long temperature time series, J. Clim. Appl. Meteorol., 47, 976-990, 2008.

Viel, M. and Ceriola, G.: Urban Heat Islands and Urban Thermography Final Report, Vol. 1, Contract no: 21913/08/I-LG (http: //www.urbanheatisland.info), 2011.

Voogt, J. A. and Oke, T. R.: Thermal remote sensing of urban climates, Remote Sens. Environ., 86, 370-384, 2003.

World Meteorological Organization: General meteorological standards and recommended practices, Appendix A, WMO Technical Regulations, WMO-No. 49, 2000.

Zhang, D. L. and Anthes, R. A.: A high-resolution model of the planetary boundary layer - sensitivity tests and comparison with SESAME-79 data, J. Appl. Meteorol., 21, 1594-1609, 1982. 